\title{
Antiangiogenic Strategies for Treatment of Malignant Gliomas
}

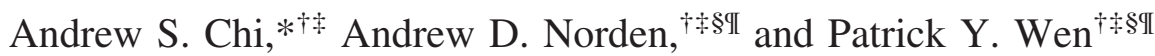 \\ *Stephen E. and Catherine Pappas Center for Neuro-Oncology, Department of Neurology, Division of Hematology and \\ Oncology, Massachusetts General Hospital Cancer Center; ${ }^{\dagger}$ Dana-Farber/Harvard Cancer Center; ${ }^{\ddagger}$ Harvard Medical School; \\ ${ }^{\S}$ Division of Neuro-Oncology, Department of Neurology, Brigham and Women's Hospital; and ${ }^{\mathbb{I I} C e n t e r}$ for Neuro-Oncology, \\ Department of Medical Oncology, Dana-Farber/Brigham and Women's Cancer Center, Boston, Massachusetts 02115
}

Summary: Numerous antiangiogenic agents with diverse mechanisms of action are currently under investigation for the treatment of patients with glioblastoma (GBM), a diagnosis that continues to carry a poor prognosis despite maximal conventional therapy. Early clinical trials suggest that antiangiogenic drugs, which target the blood vessels of these highly angiogenic tumors, may have clinical benefit in GBM patients. Antiangiogenic agents have potent antiedema and steroid-sparing effects in patients, and emerging data suggest that these drugs may modestly improve progression-free survival. Although these early results are encouraging, several issues arise regarding the use and efficacy of these agents. Interpretation of the radiographic changes that occur after treatment with antiangiogenic agents presents a major challenge. Still lacking are reliable radiographic and biologic markers that can predict which patients will benefit from treatment and that accurately indicate response and progression during therapy. In addition, most patients treated with antiangiogenic drugs eventually progress, and the mechanisms by which tumors escape from therapy are only beginning to be understood. Larger prospective trials that incorporate correlative biomarker studies will be required to address these challenges. Here, we summarize the clinical experience with antiangiogenic therapy in patients with malignant gliomas (MG), review the major issues concerning the use and development of these agents, and discuss strategies that may build upon the initial gains observed with antiangiogenic agents. Key Words: Malignant glioma, glioblastoma, angiogenesis, vascular endothelial growth factor, edema, biomarker.

\section{INTRODUCTION}

With current standard therapy, the prognosis for patients with newly diagnosed malignant glioma (MG) that is, WHO grade III gliomas (anaplastic astrocytoma, anaplastic oligodendroglioma, and anaplastic oligoastrocytoma) and WHO grade IV glioma or glioblastoma (GBM) - remains unsatisfactory. ${ }^{1}$ The standard treatment for GBM (which is the most common and aggressive malignant primary brain tumor in adults) consists of maximal safe surgical resection, radiation, and temozolomide chemotherapy and results in a median overall survival (OS) of less than 15 months. ${ }^{2}$ For patients with MG who progress through standard therapy, there is no established treatment, and these patients typically survive less than 6 months. ${ }^{3}$ Furthermore, patients with MG experience neurological deficits and considerable mor-

Address correspondence and reprint requests to: Patrick Y. Wen, M.D., Center for Neuro-Oncology, Dana-Farber/Brigham and Women's Cancer Center, SW430 D, 44 Binney St., Boston, MA 02115. E-mail: patrick_wen@dfci.harvard.edu. bidity as a result of vasogenic edema induced by tumors. Corticosteroids, the most commonly used agents to treat edema in brain tumor patients, are associated with considerable adverse effects. ${ }^{4,5}$ In recent years, however, therapeutic strategies directed at the blood vessels that supply tumors have demonstrated promise in improving the outcomes of patients with MG.

The discovery that tumor progression depends on angiogenesis (i.e., on the growth of new blood vessels from pre-existing vessels) led to the development of antiangiogenic therapy for cancer. ${ }^{6-10}$ This treatment paradigm has been proven beneficial in phase III clinical trials of several advanced solid tumors, and three antiangiogenic drugs are now approved by the U.S. Food and Drug Administration (FDA) for use in cancer patients. Bevacizumab (Avastin; Genentech, South San Francisco, CA), a humanized monoclonal antibody against vascular endothelial growth factor (VEGF), is approved for firstline therapy in combination with conventional chemotherapy in patients with advanced colorectal, non-small cell lung, and breast cancer. ${ }^{1-13}$ Sorafenib (Nexavar, Bayer, Leverkusen, Germany) and sunitinib (Sutent; 
Pfizer, New York, NY) are two tyrosine kinase inhibitors (TKI) targeting the VEGF receptor (VEGFR) that are approved for use as single agents in cancer therapy. Sorafenib is approved for use in patients with advanced renal cell and hepatocellular carcinoma ${ }^{14,15}$; sunitinib is approved for treatment of advanced renal cell carcinoma, as well as for progressive gastrointestinal (GI) stromal tumors. ${ }^{16,17}$

Growth of MG is also dependent on angiogenesis, and VEGF appears to play a primary role in the development and function of new tumor vessels. ${ }^{18-20}$ A large body of preclinical evidence suggests that antiangiogenic therapy may be effective in treating $\mathrm{MG}^{21,22}$ and preliminary clinical data suggest that antiangiogenic agents have a beneficial effect in patients with MG. ${ }^{23,24}$ Recently, the FDA Oncologic Drugs Advisory Committee voted unanimously that the response seen with bevacizumab in a recent phase II trial of patients with recurrent $\mathrm{GBM}^{25}$ is of sufficient magnitude to be reasonably likely to predict clinical benefit. As a result, the FDA granted accelerated approval for bevacizumab as a single agent for recurrent GBM patients. FDA approval of bevacizumab will naturally have major implications regarding the management of patients with recurrent GBM. Nonetheless, several issues regarding the clinical use and efficacy of angiogenesis inhibitors in MG are emerging, such as the lack of valid biomarkers of response or progression and the emergence of resistance. ${ }^{26-28}$ In this review, we focus on the current progress of clinical trials of antiangiogenic therapy in MG (FIG. 1) and on emerging issues in the clinical development of such therapy.

\section{VEGF PATHWAY INHIBITORS}

Because of its prominent role in MG tumor angiogenesis, the VEGF pathway was rapidly identified as an attractive therapeutic target. ${ }^{18-22}$ Thus, agents that target the VEGF pathway have become the most clinically advanced antiangiogenic drugs. Several VEGF-targeting approaches are under clinical investigation in MG, including strategies that target VEGF and VEGF receptors (Table 1).

\section{VEGF inhibitors}

Bevacizumab and the soluble decoy VEGF receptor aflibercept (VEGF-Trap; Regeneron, Tarrytown, NY) are VEGF-sequestering molecules characterized by long half-lives and high specificity. Several reports published over the past few years have suggested that bevacizumab may be beneficial for recurrent MG patients.

In the first reported prospective study of an anti-VEGF therapy in MG patients, high radiographic response (complete or partial response as defined by standard
Macdonald criteria) $)^{29,30}$ and 6-month progression-free survival (PFS6) proportions were observed with the combination of bevacizumab and irinotecan. ${ }^{31,32}$ In this phase II clinical trial, 68 patients (33 recurrent anaplastic glioma and 35 recurrent GBM) were treated with bevacizumab and irinotecan in two cohorts. The radiographic response proportions of $57 \%$ for recurrent GBM and $61 \%$ for anaplastic glioma patients observed ${ }^{33}$ compared favorably with response proportions seen with temozolomide at first recurrence $\left(5 \%\right.$ for recurrent $\mathrm{GBM}^{34}$ and $35 \%$ for recurrent anaplastic glioma). ${ }^{35}$ Responses were also associated with neurological improvement and reduction or discontinuation of corticosteroid requirements, indicating that a clinical benefit was derived from treatment. Furthermore, durability of the responses was suggested by an increase in the PFS6 proportions (43\% for recurrent GBM patients and 59\% for AG patients $)^{33}$ over historical benchmarks (15\% and $31 \%$, respectively). ${ }^{3}$ Although treatment was generally well tolerated, toxicity was observed; 11 of the 35 recurrent GBM patients (31\%) discontinued therapy due to treatment-related events. There were thromboembolic complications in 8 of the 68 patients overall (12\%), including one arterial stroke, and 2 patients (3\%) had CNS hemorrhages. ${ }^{33}$ Other toxicities included proteinuria, fatigue, and GI toxicity. Of note, radiographic response and PFS6 proportions were similar in the two treatment cohorts; however, the cohort with increased irinotecan dosing was associated with greater GI toxicity.

Another prospective study of 21 recurrent MG patients, of whom 17 had GBM, reported a comparably high MRI response proportion of $36 \%$ with the combination of bevacizumab and irinotecan. ${ }^{36}$ Additionally, several retrospective studies have reported similar findings with bevacizumab in recurrent MG patients. Radiographic response proportions between $35 \%$ and $50 \%$ have been observed with the combination of bevacizumab and conventional chemotherapy in several case series, with responses often occurring rapidly after treatment initiation. ${ }^{37-40}$ These studies also reported delayed tumor progression, suggesting that clinical benefits were derived. One study reported that six-month progressionfree survival was $42 \%$ for recurrent GBM patients, and an apparent antiedema effect of bevacizumab was evident, in that $33 \%$ of patients reduced their corticosteroid requirements. ${ }^{39}$

Treatment was generally well tolerated in these retrospective series, although thromboembolic and hemorrhagic complications were reported. Thromboembolic events occurred in 5 of 44 patients $(11 \%)^{39}$ and in 7 of 77 patients $(9 \%)^{40}$ in the two larger studies. Notable adverse events included six pulmonary embolisms, one superior mesenteric vein thrombosis, and one myocardial infarc- 

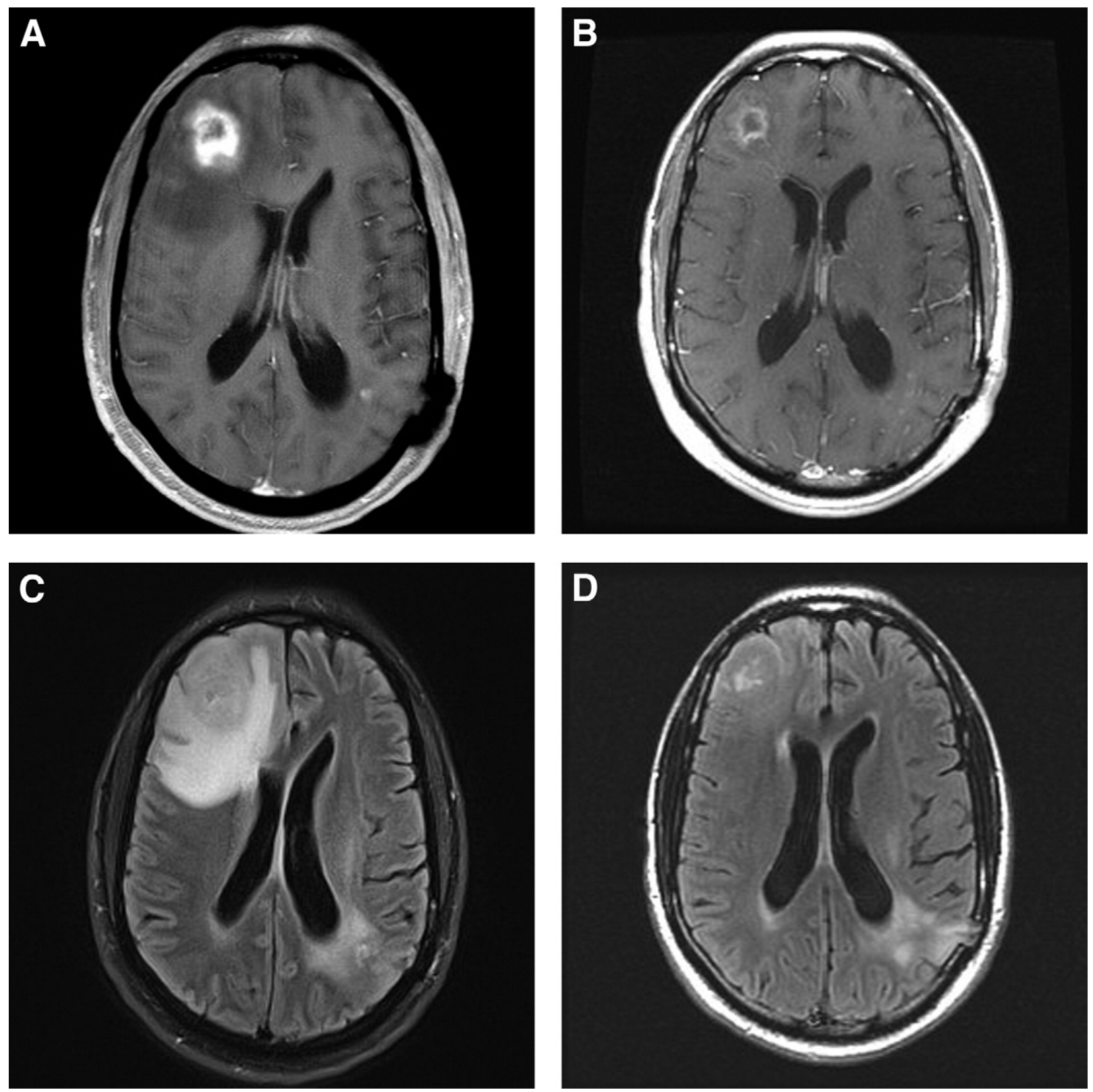

FIG 1. Axial $T_{1}$-contrast enhanced MRI of a 40 -year-old man with a multifocal recurrent glioblastoma (A) before and (B) 8 weeks after treatment with XL-184 (VEGFR and Met inhibitor) showing a significant decrease in enhancement. In the same patient, axial FLAIR MR (C) before and (D) after treatment shows the reduction in edema that correlated with symptomatic improvement.

tion (MI). Intratumoral hemorrhages were observed in 5 of 77 patients $(6.5 \%)$ in one series ${ }^{40}$, and two asymptomatic intracranial hemorrhages were noted in a series of 44 patients. ${ }^{39}$ Other adverse events of note included two GI perforations ${ }^{37,39}$ and one case of reversible posterior leukoencephalopathy syndrome. ${ }^{40}$

All of these studies were of bevacizumab in combination with cytotoxic chemotherapy. Bevacizumab was most often combined with irinotecan in these studies, and irinotecan is known to have minimal efficacy in recurrent MG patients. ${ }^{41}$ How much chemotherapy contributed to the effect of bevacizumab and whether bevacizumab possessed single-agent activity in recurrent MG patients remained unanswered. To address these questions, a phase II trial of 167 recurrent GBM randomized the patients to receive either bevacizumab alone $(10 \mathrm{mg} / \mathrm{kg}$ every 2 weeks) or in combination with irinotecan. ${ }^{25}$ The radiographic response and PFS6 proportions of 37.8\% and $50.3 \%$, respectively, observed with combination therapy were similar to the proportions seen with bevacizumab alone $\left(28.2 \%\right.$ and $42.6 \%$, respectively). ${ }^{25}$ In addition, the median OS for the combination therapy ( 8.7 months) was similar to that observed with bevacizumab alone (9.2 months). In this study, most patients were able 
Table 1. Selected Antiangiogenic Agents and Their Potential Targets Currently in Clinical Trials for Adult Malignant Glioma

\begin{tabular}{|c|c|c|}
\hline Agents & Targets & Mechanism \\
\hline \multicolumn{3}{|l|}{ VEGF inhibitors } \\
\hline Aflibercept & VEGF-A,B, PlGF & Decoy receptor \\
\hline Bevacizumab & VEGF-A & Monoclonal antibody \\
\hline \multicolumn{3}{|l|}{ VEGF receptor inhibitors } \\
\hline Cediranib & VEGFR1-3, PDGFR $\beta$, c-Kit & Tyrosine kinase inhibitor \\
\hline CT-322 & VEGFR1-3 & Fibronectin (adnectin)-based inhibitor \\
\hline Pazopanib (GW786034) & VEGFR1-3, PDGFR $\beta$, c-Kit & Tyrosine kinase inhibitor \\
\hline Sorafenib & $\begin{array}{l}\text { VEGFR2,3, BRAF, PDGFR } \beta \text {, c-Kit, } \\
\text { Ras, p38 } \alpha\end{array}$ & Tyrosine kinase inhibitor \\
\hline Sunitinib & VEGFR2, PDGFR $\beta$, Flt3, c-Kit & Tyrosine kinase inhibitor \\
\hline Vandetanib (ZD6474*) & VEGFR2, EGFR, RET & Tyrosine kinase inhibitor \\
\hline Vatalanib (PTK787) & VEGFR1-3, PDGFR $\beta$, c-Kit & Tyrosine kinase inhibitor \\
\hline XL-184 & VEGFR2, Met, RET, c-Kit, Flt3, Tie-2 & Tyrosine kinase inhibitor \\
\hline \multicolumn{3}{|l|}{ Non-VEGF pathway inhibitors } \\
\hline ABT-510 & CD36 receptor & Thrombospondin-1 mimetic peptide \\
\hline AMG 102 & $\mathrm{HGF} / \mathrm{SF}$ & Monoclonal antibody \\
\hline Brivanib & FGFR, VEGFR2 & Tyrosine kinase inhibitor \\
\hline Lenalidomide & FGF pathway & Immunomodulatory and anti-inflammatory \\
\hline Dasatinib & PDGFR $\beta$, Src, BCR-ABL, c-Kit, EphA2 & Tyrosine kinase inhibitor \\
\hline Imatinib & PDGFR $\beta$, BCR-ABL, c-Kit & Tyrosine kinase inhibitor \\
\hline Tandutinib (MLN518) & PDGFR $\beta$, Flt 3 , c-Kit & Tyrosine kinase inhibitor \\
\hline Celecoxib & $\mathrm{COX}-2$ & Suppress VEGF and FGF \\
\hline 2-methoxyestradiol $\left(2 \mathrm{ME} 2^{\dagger}\right)$ & $\mathrm{HIF}-1 \alpha$ & $\begin{array}{l}\text { Disrupt tumor microtubules and suppress } \\
\text { HIF-1a }\end{array}$ \\
\hline Metronomic temozolomide & Endothelial cells, EPCs & $\begin{array}{l}\text { Induce apoptosis, inhibit recruitment of } \\
\text { EPCs }\end{array}$ \\
\hline \multicolumn{3}{|l|}{ Endothelial cell migration inhibitors } \\
\hline ATN-161 & Integrin $\alpha 5 \beta 1$ & Fibronectin-derived PHSRN peptide \\
\hline Cilengitide & Integrins $\alpha \mathrm{v} \beta 3, \alpha \mathrm{v} \beta 5$ & RGD synthetic peptide \\
\hline
\end{tabular}

$\mathrm{BCR}-\mathrm{ABL}=$ a gene fusion protein product associated with chronic myeloid leukemia; $\mathrm{COX}=$ cyclooxygenase-2; EGFR $=$ epithelial growth factor receptor; $\mathrm{EPC}=$ endothelial progenitor cell; FGF = fibroblast growth factor; FGFR = fibroblast growth factor receptor; Flt3 = fms-related tyrosine kinase 3; HGF/SF = hepatocyte growth factor/scatter factor; HIF- $1 \alpha=$ hypoxia inducible factor $1 \alpha$; PDGFR = platelet-derived growth factor; $\mathrm{PIGF}=$ placental growth factor; $\mathrm{RA}=$ retinoic acid; $\mathrm{RT}=$ radiotherapy; $\mathrm{TMZ}=$ temozolomide; $\mathrm{VEGF}=$ vascular endothelial growth factor; VEGFR = vascular endothelial growth factor receptor.

*Trade name Zactima (Astra Zeneca). ${ }^{\dagger}$ Trade name Panzem (EntreMed).

to reduce their corticosteroid dose by at least $50 \%$, and treatment was well tolerated; intracranial hemorrhages were noted in 3 of the 167 patients.

Another recently reported phase II study evaluated the benefit of bevacizumab monotherapy in recurrent GBM patients. ${ }^{42}$ In 48 heavily pretreated patients, the authors observed a $35 \%$ radiographic response proportion and a PFS6 proportion of $29 \%$, values similar to those observed in the bevacizumab monotherapy arm of the randomized phase II trial described above. Furthermore, when irinotecan was added to bevacizumab at progression in 19 patients, there were no objective radiographic responses. Eighteen of these patients (95\%) experienced disease progression by the second cycle, and the median progression-free survival (PFS) was 30 days. These two studies suggest that irinotecan adds little, if any, benefit to bevacizumab in recurrent $M G$ patients.

Taken together, the studies of bevacizumab in recurrent MG patients indicate that bevacizumab may have clinical efficacy in this population, with a moderate but acceptable toxicity profile. The clinical utility of bevacizumab has mainly manifested as an antiedema effect and an increased PFS; however, an overall survival benefit in GBM patients has not been definitively demonstrated. Although it has been shown that PFS6 is strongly associated with OS at 12 months in recurrent GBM trials, ${ }^{43}$ recent survival data of antiangiogenic agents in recurrent MG patients are conflicting. A median OS of 9 months was observed in a recent prospective study of 61 recurrent MG patients treated with bevacizumab and chemotherapy, which the authors contended was higher than comparison historical rates of 3 to 6 months. ${ }^{44}$ However, both recurrent anaplastic glioma and GBM patients were combined in their survival analysis. In a recent retrospective analysis of recurrent GBM patients, the median OS of patients treated with antiangiogenic agents (39 weeks) was nearly identical to the median OS rate of patients treated with cytotoxic chemotherapies (37 weeks). ${ }^{45}$ Thus, it is unclear whether angiogenesis inhibitors confer a survival advantage in MG patients, and prospective, 
controlled trials are needed to address this question. Because clinical data currently indicate that any potential survival benefits with antiangiogenic agents will likely be on the order of months, many investigators are combining bevacizumab with various chemotherapy and molecularly targeted agents in recurrent MG patients to try to gain efficacy (Table 2).

Aflibercept is a soluble VEGF decoy receptor that consists of a VEGF receptor fused to an immunoglobulin constant region. It has a VEGF binding affinity several hundred times greater than bevacizumab and the capacity to also bind the VEGF family members VEGF-B and placental growth factor (PlGF). ${ }^{46}$ An ongoing phase II clinical trial of 48 recurrent MG patients treated with aflibercept monotherapy reported response proportions of $50 \%$ for anaplastic glioma and 30\% for GBM patients, ${ }^{47}$ values similar to the response proportions observed in bevacizumab trials. ${ }^{47}$ There was moderate toxicity, however, and treatment was discontinued in 12 patients (25\%), on average less than 2 months into therapy.

\section{VEGF receptor inhibitors}

Currently many VEGFR-targeted TKIs are in clinical trials for MG (Table 1). These small molecule inhibitors were initially developed as specific inhibitors of the VEGFR tyrosine kinase domain; most, however, have the capacity to inhibit many other tyrosine kinases such as the platelet-derived growth factor receptor (PDGFR), Raf, and c-Kit. ${ }^{48}$ Although this lack of specificity may result in more off-target effects, the potential for simultaneous inhibition of several proangiogenic or pathogenic signaling pathways in MG may be a favorable feature of these agents.

Cediranib (AZD2171, Recentin; AstraZeneca, London, England) is a potent pan-VEGFR TKI with modest activity against PDGFR and c-Kit. In a recent phase II trial of cediranib monotherapy in recurrent GBM patients, radiographic responses were observed in 9 of 16 patients $(56 \%)$, and $26 \%$ of patients were alive and progression-free at 6 months. ${ }^{49,50}$ There was also a modest improvement in median OS in cediranib-treated patients relative to a historical database (211 days vs 175 days). Furthermore, an antiedema effect was detected with cediranib monotherapy. Using advanced MRI techniques, the authors were able to quantify the reduction in vasogenic edema resulting from cediranib therapy, and corticosteroid requirements were discontinued or decreased in 15 of 16 patients. Toxicity was moderate. Although only 2 of 31 patients were removed from the study because of toxicity, and no treatment-related deaths or intracranial hemorrhages occurred, a high frequency of hypertension was observed, and most patients required the addition of at least one antihypertensive drug. Fatigue and diarrhea were also frequent toxicities. As a result of this study, a phase II study of cediranib, temozolomide, and radiation in newly diagnosed GBM has been launched, and a multicenter, randomized phase III trial in recurrent GBM is underway, comparing cediranib versus cediranib plus lomustine versus lomustine plus placebo.

The clinical experience with the anti-VEGF pathway agents bevacizumab and cediranib indicates that these drugs may be particularly useful in MG patients for their steroidsparing effect. ${ }^{51}$ In addition, a recent retrospective series suggested that bevacizumab was effective in reducing radiation necrosis. ${ }^{52}$ There is increasing awareness that standard treatment with concurrent chemotherapy and radiation may increase the risk of pseudoprogression, tumor necrosis, and edema. ${ }^{53-55}$ Further development of antiangiogenic therapy for the treatment of tumor edema and necrosis may be warranted, given that corticosteroids (the most common agents used to treat these indications) are associated with considerable adverse effects.

Vatalanib (PTK787; Novartis, Basel, Switzerland), an inhibitor of the VEGFR1-3, PDGFR, and c-Kit tyrosine kinases, has been clinically investigated in several advanced solid tumors. ${ }^{56}$ Several phase I/II clinical trials have studied vatalanib in recurrent GBM patients, either as monotherapy ${ }^{57}$ or in combination with either temozolomide or lomustine. ${ }^{58}$ Clinical benefits were limited in these studies; response proportions ranged between $4 \%$ and $8 \%$, and PFS proportions were not significantly higher than historical benchmarks. These results may have been affected by suboptimal dosing, however. More recently, the combination of vatalanib, the PDGFR inhibitor imatinib (Gleevec; Novartis), and hydroxyurea resulted in a modest response proportion $(22 \%)$ in a phase I trial of 37 recurrent MG patients. ${ }^{59}$

The broad-spectrum TKIs sorafenib and sunitinib have the capacity to inhibit a number of tyrosine kinases including VEGFR, PDGFR, Flt-3 and c-Kit. ${ }^{60}$ Both agents are being studied in early phase clinical trials for recurrent MG. Sorafenib, which can also inhibit Raf, is being evaluated as monotherapy and in combinations with the mammalian target of rapamycin (mTOR) inhibitor temsirolimus (Torisel; Wyeth, Madison, New Jersey) and the epidermal growth factor receptor (EGFR) inhibitor erlotinib (Tarceva; Genentech). Sunitinib is being studied as monotherapy and in combination with irinotecan. Mature data have yet to be reported, although to date these agents appear to be only moderately well tolerated. In addition, several other VEGFR inhibitors are in clinical trials for recurrent $\mathrm{MG}$ as single agents or in combination regimens (Table 2).

\section{INHIBITORS OF VEGF-INDEPENDENT ANGIOGENIC SIGNALING PATHWAYS}

A number of molecular pathways interact in complex, redundant networks to promote angiogenesis. ${ }^{8,61}$ The fi- 
Table 2. Selected Ongoing Clinical Trials of VEGF Pathway Inhibitors

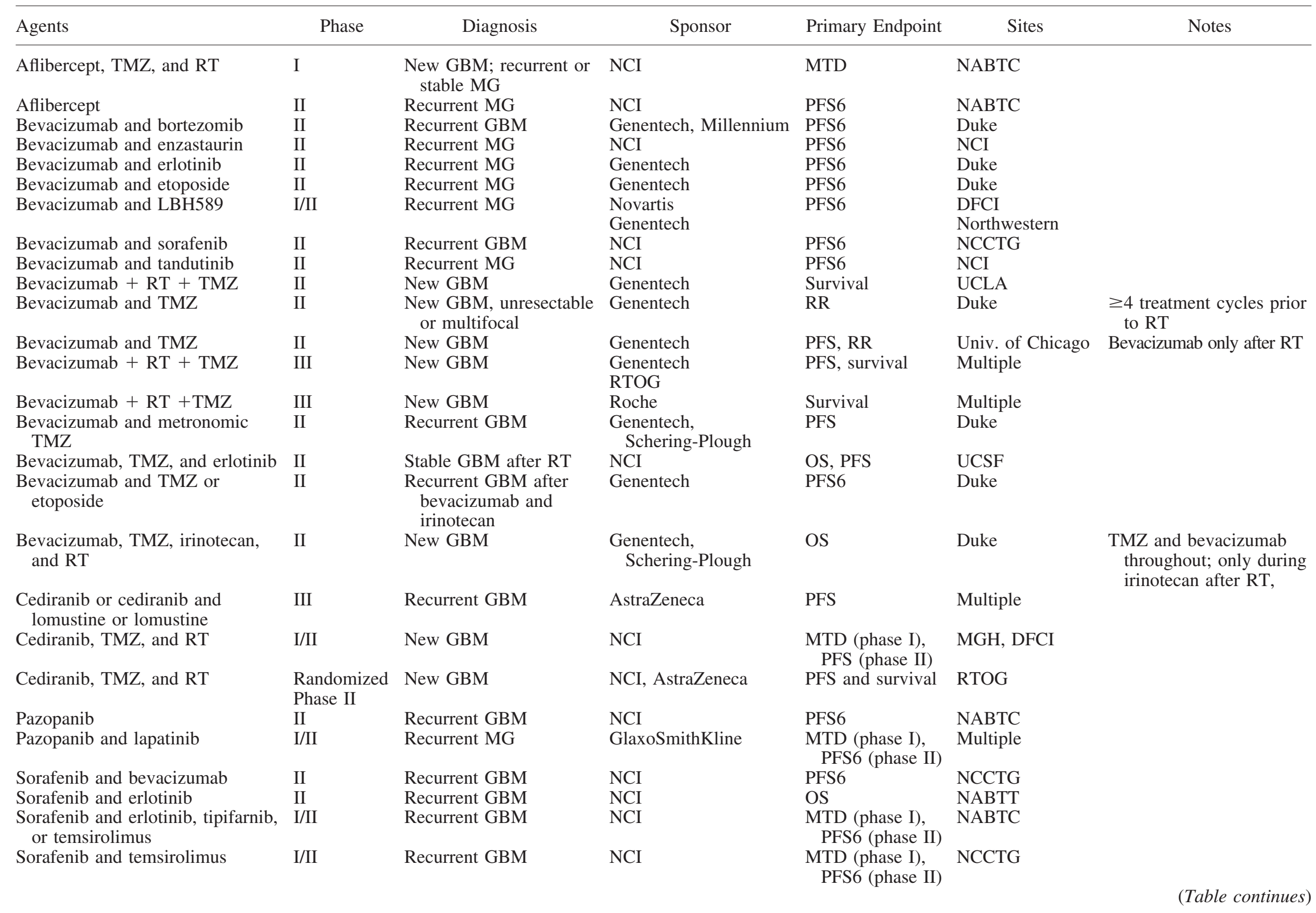




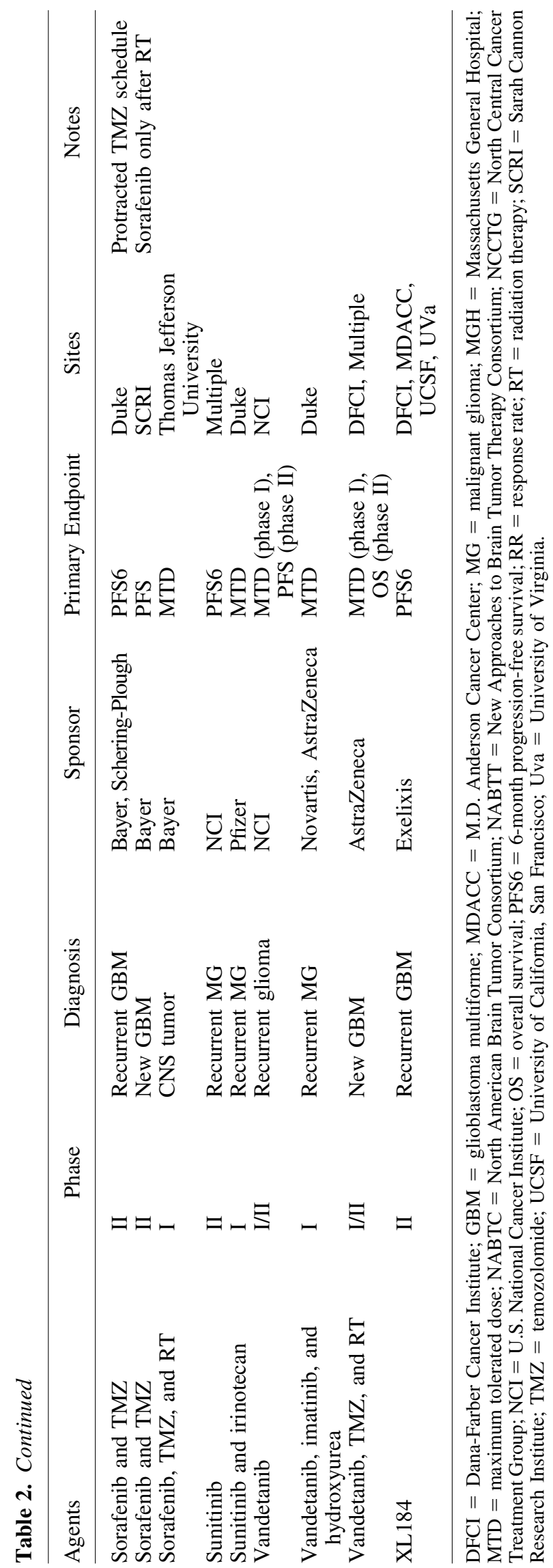

broblast growth factor (FGF) signaling pathway is an important proangiogenic pathway in GBM that is distinct from the angiogenesis driven by VEGF. Recently, the FGF pathway has been implicated in resistance to VEGF-targeted therapy. ${ }^{18,28,49}$ Strategies targeting FGF have had limited efficacy in MG patients in earlier trials; however, the inhibitors used in these studies were relatively nonspecific.

Thalidomide, an inhibitor of both basic FGF and VEGF, ${ }^{62}$ was shown to have minimal activity as monotherapy or in combinations with carmustine or temozolomide in phase II trials of MG patients. ${ }^{63-68}$ The more potent thalidomide analog lenalidomide has better tolerability; however, there was little suggestion of efficacy, either as a single agent ${ }^{69}$ or in combination with radiation therapy. ${ }^{70}$ These lenalidomide studies were phase I trials and were not designed to assess efficacy, but it is noteworthy that there were no radiographic responses with lenalidomide monotherapy in 24 recurrent GBM patients $^{69}$ and one response in 20 evaluable patients with lenalidomide in combination with radiation therapy in newly diagnosed GBM patients. ${ }^{70}$ The toxicities associated with this class of agents, which include a potentially overlapping hematologic toxicity between lenalidomide and chemotherapy, may limit further clinical development in MG.

Several other inhibitors of the FGF pathway had limited efficacy in clinical trials of MG patients, including interferon- $\alpha,{ }^{71}$ Interferon- $\beta,^{72}$ and suramin. ${ }^{73,74}$ However, FGF receptor TKIs with greater specificity for the FGF pathway have been developed; these drugs, which include TKI-258 (Novartis), XL-999 (Exelixis, South San Francisco, California), brivanib (Bristol-Myers Squibb, New York, NY), and BIBF1120 (Boehringer Ingelheim, Germany), have potential utility in MG patients.

The PDGF signaling pathway plays an important role in MG angiogenesis, as well as in glioma transformation $^{20,75,76}$, and thus represents a particularly attractive therapeutic target. However, clinical trials evaluating the PDGF receptor inhibitor imatinib as a single agent in recurrent MG patients have been disappointing. ${ }^{77,78}$ When imatinib was combined with hydroxyurea, several studies reported promising PFS6 proportions in recurrent MG patients $(24 \%-32 \%),{ }^{79-81}$ although a recent large multicenter study failed to confirm these findings. ${ }^{82}$ Given the abundance of preclinical data implicating the PDGF pathway in glioma angiogenesis and transformation, ${ }^{20}$ inhibitors of this pathway continue to be clinically investigated. A study of imatinib, hydroxyurea, and everolimus (RAD001; Novartis), an mTOR inhibitor, in recurrent MG patients is ongoing. The newer PDGF receptor TKIs tandutinib (MLN518; Millennium Phar- 
Table 3. Selected Ongoing Clinical Trials of Non-VEGF Pathway Inhibitors

\begin{tabular}{|c|c|c|c|c|c|}
\hline Agents & Phase & Diagnosis & Sponsor & $\begin{array}{l}\text { Primary } \\
\text { Endpoint }\end{array}$ & Sites \\
\hline AMG 102 & II & Recurrent MG & Amgen & RR & Multiple \\
\hline Cilengitide & III & New GBM & Merck KGaA & Survival & Multiple \\
\hline Dasatinib and erlotinib & I & recurrent $\mathrm{MG}$ & $\begin{array}{l}\text { Bristol-Myers Squibb, } \\
\text { Genentech }\end{array}$ & MTD & Duke \\
\hline Dasatinib & II & Recurrent GBM & RTOG & RR or PFS6 & RTOG \\
\hline Imatinib, everolimus, and hydroxyurea & I & Recurrent MG & Novartis & MTD & Duke \\
\hline Imatinib and TMZ & I & $\begin{array}{l}\text { Stable or recurrent } \\
\text { MG in first } \\
\text { relapse }\end{array}$ & NCI & MTD & Duke \\
\hline Imatinib, vandetanib, and hydroxyurea & I & Recurrent MG & Novartis, AstraZeneca & MTD & Duke \\
\hline Tandutinib & $\mathrm{I} / \mathrm{II}$ & Recurrent GBM & $\mathrm{NCI}$ & $\begin{array}{l}\text { MTD (phase I) } \\
\text { RR (phase II) }\end{array}$ & NABTT \\
\hline Tandutinib and bevacizumab & II & Recurrent MG & NCI & PFS6 & $\mathrm{NCI}$ \\
\hline $\begin{array}{l}\text { TMZ or lomustine }+6-\mathrm{TG} \text {, capecitabine, } \\
\text { or celecoxib }\end{array}$ & II & Recurrent MG & MDACC & PFS12 & MDACC \\
\hline $\begin{array}{l}\text { TMZ } \pm \text { thalidomide and/or cis-retinoic } \\
\text { acid and/or celecoxib }\end{array}$ & II & $\begin{array}{l}\text { Stable GBM after } \\
\text { RT }\end{array}$ & NCI & PFS6 & MDACC \\
\hline
\end{tabular}

$\mathrm{GBM}=$ glioblastoma multiforme; MDACC $=$ M.D. Anderson Cancer Center; $\mathrm{MG}=$ malignant glioma; $\mathrm{MTD}=$ maximum tolerated dose $\mathrm{NABTC}=$ North American Brain Tumor Consortium; NABTT $=$ New Approaches to Brain Tumor Therapy consortium; NCI $=$ U.S National Cancer Institute; PFS12 = 12-month progression-free survival; PFS6 $=6$-month progression-free survival; RR $=$ response rate; $\mathrm{RT}=$ radiation therapy; $\mathrm{RTOG}=$ Radiation Therapy Oncology Group; TMZ $=$ temozolomide.

maceuticals, Cambridge, MA) and dasatanib (Sprycel; Bristol-Myers Squibb) have potentially greater efficacy in MG patients, due to improved CNS penetration, and are in clinical trials for recurrent MG (Table 3).

Other angiogenic pathways have been targeted in MG patients, although efficacy has been limited in these studies. Signaling through the protein kinase C (PKC) pathway plays an important role in MG angiogenesis. The PKC- $\beta$ inhibitor enzastaurin (LY317615; Eli Lilly, Indianapolis, IN) was evaluated as monotherapy in a phase III randomized trial, compared against lomustine, in recurrent GBM; however, the study was halted on interim analysis because efficacy milestones were not met. ${ }^{83} \mathrm{Cy}$ clooxygenase-2 (COX-2), which promotes the expression of proangiogenic factors, ${ }^{84}$ has been targeted in recurrent MG patients with the selective COX2 inhibitor celecoxib (Celebrex, Pfizer). However, only modest PFS6 proportions of $19 \%$ and $25 \%$ were observed when celecoxib was combined with irinotecan and 13-cis-retinoic acid, respectively. ${ }^{85,86}$

The hepatocyte growth factor/scatter factor (HGF/SF) pathway is another important mediator of glioma angiogenesis. ${ }^{87,88}$ There has been increased interest in targeting $\mathrm{HGF} / \mathrm{SF}$ and its cognate tyrosine kinase receptor, c-Met, in MG. Drugs in clinical development for MG that target the c-Met pathway include AMG 102, a fully human monoclonal antibody against $\mathrm{HGF} / \mathrm{SF}$, and XL184, a c-Met TKI that also inhibits the VEGFR2 and RET tyrosine kinases.

\section{INHIBITORS OF ENDOTHELIAL CELL MIGRATION}

The $\alpha \nu \beta 3$ and $\alpha \nu \beta 5$ integrins, which are cell surface receptors that promote endothelial cell migration and survival during angiogenesis, represent attractive therapeutic targets. ${ }^{89}$ The competitive $\alpha \nu \beta 3$ and $\alpha \nu \beta 5$ integrin inhibitor cilengitide (EMD121974; Merck, Whitehouse Station, NJ) has demonstrated modest activity in several recent clinical trials of MG patients. In a randomized phase II trial, 81 patients with GBM in first recurrence were treated with cilengitide in one of two dose cohorts. Although the drug was well tolerated, cilengitide exhibited only modest antitumor activity. ${ }^{90}$ A radiographic response proportion of $13 \%$ and a PFS6 proportion of $15 \%$ was observed in the higher dose cohort, with $2000 \mathrm{mg}$ administered twice weekly. A randomized phase II trial reported promising efficacy results using cilengitide in newly diagnosed GBM patients in which 81 patients were randomized to receive either cilengitide in addition to standard therapy (radiotherapy and temozolomide) or standard therapy alone. ${ }^{91}$ The primary endpoint was successfully reached; the proportion of patients treated with cilengitide that were progression-free at 6 months (65.4\%) was significantly higher than the PFS6 proportion achieved with standard therapy alone $(53.6 \%) .{ }^{91}$ Patients with the methylated $O$-6-methylguanine-DNA methyltransferase (MGMT) gene promoter appeared to derive the greatest benefit. 
Cilengitide toxicity appears to be minimal: no maximum tolerated dose was defined in two phase I studies of cilengitide monotherapy. ${ }^{92,93}$ In the randomized trial of cilengitide in newly diagnosed GBM patients, toxicity was similar in both arms of the study. ${ }^{91}$ In addition, a recent clinical study observed good tumor penetration after intravenous drug administration. ${ }^{94}$ Based on these encouraging results, a multicenter randomized phase III trial is underway using cilengitide in newly diagnosed GBM with methylated $M G M T$ gene promoter.

\section{METRONOMIC CHEMOTHERAPY}

Conventional chemotherapy administered at low doses on a frequent or continuous schedule, referred to as metronomic chemotherapy, has been shown to target mainly the endothelial cells of growing tumor vasculature. ${ }^{95} \mathrm{In}$ glioma animal models, metronomic chemotherapy is an effective antiangiogenic strategy. ${ }^{96}$ Earlier studies evaluating metronomic chemotherapy in recurrent MG patients reported favorable toxicity profiles, but no significant survival benefits were observed. ${ }^{97-99}$ Recently, two reports evaluating low-dosed, frequently administered temozolomide schedules in recurrent GBM patients documented modest gains in PFS6 proportions, relative to historical controls. ${ }^{100,101}$ Clinical trials evaluating the addition of bevacizumab to metronomic chemotherapy are ongoing, as this strategy has greater antiangiogenic efficacy in preclinical models. ${ }^{102}$ It should be noted, however, that antitumor activity of prolonged temozolomide dosing could also be attributed to the higher cumulative doses and the MGMT enzyme depletion that these schedules achieve. ${ }^{103}$

\section{CURRENT CHALLENGES IN THE CLINICAL DEVELOPMENT OF ANTIANGIOGENIC THERAPY}

The compendium of clinical data regarding antiangiogenic agents suggests that these drugs may have modest clinical benefit in a subset of MG patients. This benefit is reflected in an apparent antiedema and steroid-sparing effect, improvements in radiographic response proportions, and a prolonged PFS. Bevacizumab and irinotecan combination therapy is thus frequently used for patients with progressive MG. Nonetheless, a number of issues remain unresolved concerning the clinical use of these drugs, including issues of resistance, radiographic assessment, biomarkers, and toxicity profiles.

\section{Resistance}

Clinical data suggest that benefits gained from antiangiogenic agents will be short-lived, with any potential improvements in survival likely measurable in months. Almost all MG patients treated with antiangiogenic in- hibitors progress during therapy, as tumors eventually acquire an evasive resistance. After treatment with bevacizumab and chemotherapy fails in MG patients, tumor progression is usually rapid. In a recent series, MG patients treated with a second bevacizumab-containing regimen after progression during treatment with a first bevacizumab regimen had a median PFS of only 37.5 days. ${ }^{104}$

Several mechanisms of resistance to angiogenesis inhibitors have been proposed in GBM. ${ }^{28,61}$ Tumors may induce revascularization by activating alternate proangiogenic signaling pathways in response to VEGF inhibition. $^{28,49,61,105}$ In recurrent GBM, patients who progressed during cediranib treatment had elevated levels of circulating bFGF, SDF $1 \alpha$, and Tie-2, factors that are mediators of alternative proangiogenic pathways. ${ }^{49}$

A second mechanism of resistance involves the recruitment of vascular progenitor cells and proangiogenic monocytes from the bone marrow. ${ }^{106}$ Hypoxia, by inducing hypoxia-inducible factor $1 \alpha$ and its targets $\operatorname{SDF} 1 \alpha$ and VEGF, attracts a heterogeneous population of bonemarrow-derived cells. Endothelial and pericyte progenitors are recruited to the tumor and are directly incorporated as components of new blood vessels, while specific monocytes that are recruited produce proangiogenic factors that facilitate neovascularization. ${ }^{107,108}$

It is increasingly recognized that anti-VEGF therapy may elicit MG tumors to adopt a more invasive phenotype, one that is less dependent on angiogenesis. A number of years ago, experiments in intracranial glioma mouse models demonstrated that VEGF inhibition with antibodies directed against either VEGF or VEGFR generated more invasive tumors that continued to grow by co-opting pre-existing blood vessels. ${ }^{109,110}$ These findings were reproduced in recent preclinical experiments using small molecule inhibitors of VEGFR and tumors lacking VEGF. ${ }^{111}$ Together, these studies suggest that anti-VEGF therapy may be changing the natural history of tumors by inducing heightened tumor cell invasiveness and, in solid tumor models, enhancing distant metastasis. ${ }^{111,112}$ In GBM patients, enhanced infiltration by MRI characteristics have been reported in subsets of patients treated with bevacizumab. ${ }^{39,44}$ In these patients, the infiltrating tumor appeared as areas of noncontrastenhancing increased $T_{2}$ or fluid attenuated inversion recovery (FLAIR) signal.

In addition to patients who become resistant after initially responding to anti-VEGF agents, a subset of patients may be intrinsically resistant to therapy. ${ }^{28,49}$ Evidence in late-stage breast cancer patients suggests that nonresponding patients may have pre-existing activation of parallel VEGF-independent angiogenic pathways. ${ }^{113}$ A recent analysis of tissue obtained from newly diagnosed MG patients suggested that VEGF-independent tumor edema may be mediated by neuronal pentraxin 2 
and aquaporin-3. ${ }^{114}$ An increasing number of clinical trials are simultaneously targeting multiple proangiogenic pathways to try to pre-empt intrinsic resistance (Table 2).

Lastly, a recent preclinical study demonstrated that survival improvements in mice treated with an antiVEGF agent were primarily due to alleviation of edema. ${ }^{115}$ Animals treated with cediranib had increased survival and decreased tumor-associated edema, but there was no inhibition of tumor growth, and their intracranial glioma xenografts continued to enlarge during treatment. Similar effects on survival, edema, and tumor growth were seen in mice treated with dexamethasone alone. This study raises the possibility that tumors may not develop resistance per se. Treatment failure may be due to the inability of anti-VEGF drugs to control cerebral edema and continued enlargement of the tumor rather than to tumor evasive mechanisms. It remains to be determined, however, whether these preclinical studies generalize to other anti-VEGF compounds and to human tumors.

\section{Radiographic assessment of tumor response and progression}

Many studies have reported high radiographic response proportions in MG patients treated with antiangiogenic agents. It is becoming apparent, however, that obtaining accurate assessments of response to antiangiogenic therapy is problematic in brain tumor patients. ${ }^{30}$ Standard response criteria currently in use for assessing treatment response in brain tumors are dependent on contrast-enhancement on CT or MRI. ${ }^{29}$ However, contrast-enhancement on CT and MRI scans reflects VEGFmediated blood-brain barrier dysfunction and may not be an authentic representation of the underlying tumor. Moreover, anti-VEGF agents decrease permeability of cerebral vessels and diminish the contrast enhancement on standard MRI, ${ }^{49}$ making it difficult to distinguish antitumor effects of treatment from the effects of these drugs on blood vessel permeability.

Establishing a reliable measure of treatment response and progression in GBM patients treated with antiangiogenic agents is therefore of paramount importance. An international Response Assessment in Neuro-Oncology working group is currently updating the standard response criteria to address these challenges. Newer imaging techniques that provide functional information may have greater reliability in assessing tumor activity during antiangiogenic treatment. Dynamic contrast-enhanced MRI (DCE-MRI), diffusion-weighted MRI, positron emission tomography (PET), and MRI-PET fusion techniques have potential utility in this setting. ${ }^{36,116-119}$ These techniques, however, await validation. A small prospective study reported that $\left[{ }^{18} \mathrm{~F}\right]$ fluorothymidine (FLT) PET response at 1 to 2 weeks after initiation of bevacizumab and irinotecan therapy was predictive of
OS in recurrent MG patients. ${ }^{36}$ This finding requires validation in larger prospective trials.

\section{Biomarkers}

Although several imaging modalities have potential utility in assessing response or progression, there is a need for validated circulating or tissue biomarkers that can accurately predict antiangiogenic efficacy and indicate progression during treatment. Several blood and tissue components have been identified as candidate biomarkers. ${ }^{27}$ A recent study suggests that VEGF protein expression in tumor tissue may be predictive for radiographic response in patients treated with bevacizumab. ${ }^{120}$ This same study reported tumor expression of hypoxia-induced carbonic anhydrase 9 (CA9) was associated with shorter survival. In recurrent GBM patients, radiographic tumor progression during cediranib treatment was associated with elevated levels of bFGF, SDF1 $\alpha$, Tie-2, and circulating endothelial cells. ${ }^{49}$ That study and others have shown that serum VEGF and PIGF are significantly elevated in patients being treated with anti-VEGF therapy. ${ }^{49,121}$ These serum markers have potential utility as pharmacodynamic or pharmacokinetic biomarkers during anti-VEGF therapy. Validation of these preliminary findings in large prospective cohorts will be necessary.

\section{Toxicity profile}

The risks of hemorrhage and thrombosis have been ongoing concerns with the use of antiangiogenic therapy in MG patients. Cumulative toxicity data indicate that major systemic bleeding is rare, but the risk of epistaxis is increased. The intracranial hemorrhage risk appears to be low, and events are often asymptomatic. Intriguingly, one study treated 11 patients with concurrent antiangiogenic and anticoagulation therapies, and only one episode of mild epistaxis was observed. ${ }^{39}$ Although some reports suggest an increased risk of thromboembolic events in MG patients treated with bevacizumab, ${ }^{32}$ this risk has been difficult to assess, because patients with GBM have an intrinsically higher risk of thrombosis. ${ }^{122}$

It appears that some toxicities are shared by all inhibitors of angiogenesis, but certain toxicities are associated with specific classes of antiangiogenic agents. Toxicities common to both anti-VEGF antibodies and VEGFR TKIs include fatigue and hypertension. Impaired wound healing is observed, and may be problematic in treating newly diagnosed GBM patients immediately after surgery. ${ }^{123}$ Hemorrhage and GI perforation are less frequently observed. With TKIs, skin toxicity, hypertension, diarrhea, and mucositis are more commonly observed, whereas proteinuria is more frequent with bevacizumab. Other rare but serious complications noted with antiangiogenic therapy include myocardial infarction, arterial stroke, reversible posterior leukoencepha- 
lopathy syndrome, and thrombotic thrombocytopenic purpura. $^{33,124,125}$

\section{CONCLUSIONS AND FUTURE DIRECTIONS}

In summary, current evidence suggests that angiogenesis inhibitors may have clinical utility for MG patients. Clinical benefits have manifested primarily as steroidsparing effects and increased progression-free survival. Nonetheless, a definite survival advantage has yet to be established with these drugs. Several issues and obstacles remain in the clinical development of antiangiogenic agents in MG, and their resolution may result in improvements in efficacy.

In most MG patients, tumors ultimately become resistant to therapy, often characterized by an increased invasiveness that is difficult to assess and difficult to treat. Because of to the antipermeability effects of VEGF inhibitors, radiographic assessments of response and progression are challenging. Validated biomarkers that predict clinical efficacy, monitor tumor response, and indicate tumor progression do not yet exist. Furthermore, angiogenesis inhibitors possess a unique set of toxicities that are still being characterized in MG patients. Nevertheless, the FDA recently approved bevacizumab for use in recurrent GBM patients, based on the clinical benefits observed in two recent phase II trials. ${ }^{25,42}$ This approval represents a milestone in the management of GBM patients, in that bevacizumab would be the first targeted agent with clinical efficacy in this population.

Ongoing clinical trials will address several open questions, including the role of antiangiogenic therapy in newly diagnosed patients. Based on encouraging clinical results in recurrent MG patients, many trials are investigating the addition of antiangiogenic drugs to standard first-line therapy for GBM. Bevacizumab, ${ }^{123,126}$ cediranib, vandentanib, aflibercept, XL184, and cilengitide are being evaluated in combination with standard therapy in newly diagnosed GBM patients. Other trials are evaluating combinations of antiangiogenic therapy with different cytotoxic agents or targeted agents in recurrent MG patients in attempts to improve upon the efficacy gains already observed.

Going forward, prospective randomized controlled trials that use survival as an endpoint will be required to determine whether antiangiogenic strategies increase survival of MG patients. Furthermore, clinical trials with well-integrated correlative imaging and molecular studies will be critical to overcoming the challenges that remain. Finally, it is apparent that greater understanding of glioma angiogenesis, the most important angiogenic targets, and the mechanisms of treatment resistance are required. Results from further preclinical investigations and integrative clinical studies may lead to new insights that will hopefully result in improved outcomes for patients with these refractory tumors.

Acknowledgment: We gratefully acknowledge the support of the Melinda Wanatick Brain Tumor Research Fund.

\section{REFERENCES}

1. Wen PY, Kesari S. Malignant gliomas in adults. N Engl J Med 2008;359:492-507.

2. Stupp R, Mason WP, van den Bent MJ, et al. Radiotherapy plus concomitant and adjuvant temozolomide for glioblastoma. N Engl J Med 2005;352:987-996.

3. Wong ET, Hess KR, Gleason MJ, et al. Outcomes and prognostic factors in recurrent glioma patients enrolled onto phase II clinical trials. J Clin Oncol 1999;17:2572-2578.

4. van de Beek D. Brain teasing effect of dexamethasone. Lancet Neurol 2007;6:203-204.

5. Drappatz J, Schiff D, Kesari S, Norden AD, Wen PY. Medical management of brain tumor patients. Neurol Clin 2007;25:103571 , ix.

6. Folkman J. Tumor angiogenesis: therapeutic implications. N Engl J Med 1971;285:1182-1186.

7. Folkman J. Angiogenesis. Annu Rev Med 2006;57:1-18.

8. Carmeliet P, Jain RK. Angiogenesis in cancer and other diseases. Nature 2000;407:249-257.

9. Kerbel RS. Tumor angiogenesis. N Engl J Med 2008;358:20392049.

10. Folkman J. Angiogenesis: an organizing principle for drug discovery? Nat Rev Drug Discov 2007;6:273-286.

11. Hurwitz H, Fehrenbacher L, Novotny W, et al. Bevacizumab plus irinotecan, fluorouracil, and leucovorin for metastatic colorectal cancer. N Engl J Med 2004;350:2335-2342.

12. Sandler A, Gray R, Perry MC, et al. Paclitaxel-carboplatin alone or with bevacizumab for non-small-cell lung cancer. N Engl J Med 2006;355:2542-2550.

13. Miller K, Wang M, Gralow J, et al. Paclitaxel plus bevacizumab versus paclitaxel alone for metastatic breast cancer. N Engl J Med 2007;357:2666-2676.

14. Escudier B, Eisen T, Stadler WM, et al. Sorafenib in advanced clear-cell renal-cell carcinoma. N Engl J Med 2007;356:125-134.

15. Llovet JM, Ricci S, Mazzaferro V, et al. Sorafenib in advanced hepatocellular carcinoma. N Engl J Med 2008;359:378-390.

16. Motzer RJ, Hutson TE, Tomczak P, et al. Sunitinib versus interferon alfa in metastatic renal-cell carcinoma. $\mathrm{N}$ Engl $\mathrm{J}$ Med 2007;356:115-124.

17. Demetri GD, van Oosterom AT, Garrett CR, et al. Efficacy and safety of sunitinib in patients with advanced gastrointestinal stromal tumour after failure of imatinib: a randomised controlled trial. Lancet 2006;368:1329-1338.

18. Fischer I, Gagner JP, Law M, Newcomb EW, Zagzag D. Angiogenesis in gliomas: biology and molecular pathophysiology. Brain Pathol 2005;15:297-310.

19. Kargiotis O, Rao JS, Kyritsis AP. Mechanisms of angiogenesis in gliomas. J Neurooncol 2006;78:281-293.

20. Jain RK, di Tomaso E, Duda DG, Loeffler JS, Sorensen AG, Batchelor TT. Angiogenesis in brain tumours. Nat Rev Neurosci 2007;8:610-622.

21. Winkler F, Kozin SV, Tong RT, et al. Kinetics of vascular normalization by VEGFR 2 blockade governs brain tumor response to radiation: role of oxygenation, angiopoietin-1, and matrix metalloproteinases. Cancer Cell 2004;6:553-563.

22. Gagner JP, Law M, Fischer I, Newcomb EW, Zagzag D. Angiogenesis in gliomas: imaging and experimental therapeutics. Brain Pathol 2005; 15:342-363.

23. Reardon DA, Desjardins A, Rich JN, Vredenburgh JJ. The emerging role of anti-angiogenic therapy for malignant glioma. Curr Treat Options Oncol 2008;9:1-22.

24. Norden AD, Drappatz J, Wen PY. Antiangiogenic therapy in malignant gliomas. Curr Opin Oncol 2008;20:652-661.

25. Cloughesy TF, Prados MD, Wen PY, et al. A phase II, randomized, non-comparative clinical trial of the effect of bevacizumab 
(BV) alone or in combination with irinotecan (CPT) on 6-month progression free survival (PFS6) in recurrent, treatment-refractory glioblastoma (GBM). J Clin Oncol 2008;26(May 20 Suppl):A2010b (abstract).

26. Jain RK, Duda DG, Clark JW, Loeffler JS. Lessons from phase III clinical trials on anti-VEGF therapy for cancer. Nat Clin Pract Oncol 2006;3:24-40.

27. Duda DG, Batchelor TT, Willett CG, Jain RK. VEGF-targeted cancer therapy strategies: current progress, hurdles and future prospects. Trends Mol Med 2007;13:223-230.

28. Bergers G, Hanahan D. Modes of resistance to anti-angiogenic therapy. Nat Rev Cancer 2008;8:592-603.

29. Macdonald DR, Cascino TL, Schold SCJ, Cairncross JG. Response criteria for phase II studies of supratentorial malignant glioma. J Clin Oncol 1990;8:1277-1280.

30. Sorensen AG, Batchelor TT, Wen PY, Zhang WT, Jain RK. Response criteria for glioma. Nat Clin Pract Oncol 2008;5:634644.

31. Vredenburgh JJ, Desjardins A, Herndon JEn, et al. Phase II trial of bevacizumab and irinotecan in recurrent malignant glioma. Clin Cancer Res 2007;13:1253-1259.

32. Vredenburgh JJ, Desjardins A, Herndon JE 2nd, et al. Bevacizumab plus irinotecan in recurrent glioblastoma multiforme. J Clin Oncol 2007;25:4722-4729.

33. Wagner SA, Desjardins A, Reardon DA, et al. Update on survival from the original phase II trial of bevacizumab and irinotecan in recurrent malignant gliomas. J Clin Oncol 2008;26 (May 20 Suppl):abstract 2021.

34. Yung WK, Albright RE, Olson J, et al. A phase II study of temozolomide vs. procarbazine in patients with glioblastoma multiforme at first relapse. Br J Cancer 2000;83:588-593.

35. Yung WK, Prados MD, Yaya-Tur R, et al.; Temodal Brain Tumor Group. Multicenter phase II trial of temozolomide in patients with anaplastic astrocytoma or anaplastic oligoastrocytoma at first relapse. J Clin Oncol 1999;17:2762-2771.

36. Chen W, Delaloye S, Silverman DH, et al. Predicting treatment response of malignant gliomas to bevacizumab and irinotecan by imaging proliferation with $[18 \mathrm{~F}]$ fluorothymidine positron emission tomography: a pilot study. J Clin Oncol 2007;25:47144721.

37. Stark-Vance V. Bevacizumab and CPT-11 in the treatment of relapsed malignant glioma. Neuro Oncol 2005;7:369 (abstract 342).

38. Pope WB, Lai A, Nghiemphu P, Mischel P, Cloughesy TF. MRI in patients with high-grade gliomas treated with bevacizumab and chemotherapy. Neurology 2006;66:1258-1260.

39. Norden AD, Young GS, Setayesh K, et al. Bevacizumab for recurrent malignant gliomas: efficacy, toxicity, and patterns of recurrence. Neurology 2008;70:779-787.

40. Guiu S, Taillibert S, Chinot O, et al. Bevacizumab/irinotecan: an active treatment for recurrent high grade gliomas: preliminary results of an ANOCEF multicenter study [In French]. Rev Neurol (Paris) 2008;164:588-594.

41. Batchelor TT, Gilbert MR, Supko JG, et al. Phase 2 study of weekly irinotecan in adults with recurrent malignant glioma: final report of NABTT 97-11. Neuro Oncol 2004;6:21-27.

42. Kreisl TN, Kim L, Moore K, et al. Phase II trial of single-agent bevacizumab followed by bevacizumab plus irinotecan at tumor progression in recurrent glioblastoma. J Clin Oncol 2009;27:740745.

43. Ballman KV, Buckner JC, Brown PD, et al. The relationship between six-month progression-free survival and 12-month overall survival end points for phase II trials in patients with glioblastoma multiforme. Neuro Oncol 2007;9:29-38.

44. Narayana A, Kelly P, Golfinos J, et al. Antiangiogenic therapy using bevacizumab in recurrent high-grade glioma: impact on local control and patient survival. J Neurosurg 2009;110:173180.

45. Norden AD, Drappatz J, Muzikansky A, et al. An exploratory survival analysis of anti-angiogenic therapy for recurrent malignant glioma. J Neurooncol 2009;92:149-155.

46. Holash J, Davis S, Papadopoulos N, et al. VEGF-Trap: a VEGF blocker with potent antitumor effects. Proc Natl Acad Sci U S A 2002;99:11393-11398.

47. De Groot JF, Wen PY, Lamborn K, et al. Phase II single arm trial of aflibercept in patients with recurrent temozolomide-resistant glioblastoma: NABTC 0601. J Clin Oncol 2008;26(May 20 Suppl):abstract 2020.

48. Karaman MW, Herrgard S, Treiber DK, et al. A quantitative analysis of kinase inhibitor selectivity. Nat Biotechnol 2008;26: $127-132$.

49. Batchelor TT, Sorensen AG, di Tomaso E, et al. AZD2171, a pan-VEGF receptor tyrosine kinase inhibitor, normalizes tumor vasculature and alleviates edema in glioblastoma patients. Cancer Cell 2007;11:83-95.

50. Batchelor T, Sorensen G, di Tomaso E, et al. A multidisciplinary phase II study of AZD2171 (cediranib), an oral pan-VEGF receptor tyrosine kinase inhibitor, in patients with recurrent glioblastoma. AACR Meet Abstr 2008 (abstract LB-247).

51. Gerstner ER, Duda DG, di Tomaso E, et al. VEGF inhibitors in the treatment of cerebral edema in patients with brain cancer. Nat Rev Clin Oncol 2009;6:229-236.

52. Gonzalez J, Kumar AJ, Conrad CA, Levin VA. Effect of bevacizumab on radiation necrosis of the brain. Int J Radiat Oncol Biol Phys 2007;67:323-326.

53. Chamberlain MC, Glantz MJ, Chalmers L, Van Horn A, Sloan AE. Early necrosis following concurrent Temodar and radiotherapy in patients with glioblastoma. J Neurooncol 2007;82:81-83.

54. Brandsma D, Stalpers L, Taal W, Sminia P, van den Bent MJ. Clinical features, mechanisms, and management of pseudoprogression in malignant gliomas. Lancet Oncol 2008;9:453-461.

55. Taal W, Brandsma D, de Bruin HG, et al. Incidence of early pseudo-progression in a cohort of malignant glioma patients treated with chemoirradiation with temozolomide. Cancer 2008; 113:405-410.

56. Thomas AL, Morgan B, Horsfield MA, et al. Phase I study of the safety, tolerability, pharmacokinetics, and pharmacodynamics of PTK787/ZK 222584 administered twice daily in patients with advanced cancer. J Clin Oncol 2005;23:4162-4171.

57. Conrad C, Friedman H, Reardon D, et al. A phase I/II trial of single-agent PTK 787/ZK 222584 (PTK/ZK), a novel, oral angiogenesis inhibitor, in patients with recurrent glioblastoma multiforme (GBM). J Clin Oncol 2004;22, 14S (July 15 Suppl): abstract 1512 .

58. Reardon D, Friedman H, Brada M, et al. A Phase I/II trial of PTK 787/ZK 222584 (PTK/ZK), a multi-VEGF receptor tyrosine kinase inhibitor, in combination with either temozolomide or lomustine for patients with recurrent glioblastoma multiforme (GBM). Neuro Oncol 2004;6:TA-48 (abstract).

59. Kirkpatrick JP, Rich JN, Vredenburgh JJ, et al. Final report: Phase I trial of imatinib mesylate, hydroxyurea, and vatalanib for patients with recurrent malignant glioma (MG). J Clin Oncol 2008;26(May 20 Suppl):abstract 2057.

60. Morabito A, De Maio E, Di Maio M, Normanno N, Perrone F. Tyrosine kinase inhibitors of vascular endothelial growth factor receptors in clinical trials: current status and future directions. Oncologist 2006;11:753-764.

61. Ellis LM, Hicklin DJ. Pathways mediating resistance to vascular endothelial growth factor-targeted therapy. Clin Cancer Res 2008;14:6371-6375.

62. D'Amato RJ, Loughnan MS, Flynn E, Folkman J. Thalidomide is an inhibitor of angiogenesis. Proc Natl Acad Sci U S A 1994;91: 4082-4085.

63. Marx GM, Pavlakis N, McCowatt S, et al. Phase II study of thalidomide in the treatment of recurrent glioblastoma multiforme. J Neurooncol 2001;54:31-38.

64. Short SC, Traish D, Dowe A, Hines F, Gore M, Brada M. Thalidomide as an anti-angiogenic agent in relapsed gliomas. J Neurooncol 2001;51:41-45.

65. Fine HA, Figg WD, Jaeckle K, et al. Phase II trial of the antiangiogenic agent thalidomide in patients with recurrent high-grade gliomas. J Clin Oncol 2000;18:708-715.

66. Fine HA, Wen PY, Maher EA, et al. Phase II trial of thalidomide and carmustine for patients with recurrent high-grade gliomas. J Clin Oncol 2003;21:2299-2304. 
67. Baumann F, Bjeljac M, Kollias SS, et al. Combined thalidomide and temozolomide treatment in patients with glioblastoma multiforme. J Neurooncol 2004;67:191-200.

68. Chang SM, Lamborn KR, Malec M, et al. Phase II study of temozolomide and thalidomide with radiation therapy for newly diagnosed glioblastoma multiforme. Int J Radiat Oncol Biol Phys 2004;60:353-357.

69. Fine HA, Kim L, Albert PS, et al. A phase I trial of lenalidomide in patients with recurrent primary central nervous system tumors. Clin Cancer Res 2007;13:7101-7106.

70. Drappatz J, Wong ET, Schiff D, et al. A pilot safety study of lenalidomide and radiotherapy for patients with newly diagnosed glioblastoma multiforme. Int J Radiat Oncol Biol Phys 2009;73: 222-227.

71. Buckner JC, Schomberg PJ, McGinnis WL, et al. A phase III study of radiation therapy plus carmustine with or without recombinant interferon-alpha in the treatment of patients with newly diagnosed high-grade glioma. Cancer 2001;92:420-433.

72. Fine HA, Wen PY, Robertson M, et al. A phase I trial of a new recombinant human beta-interferon (BG9015) for the treatment of patients with recurrent gliomas. Clin Cancer Res 1997;3:381387.

73. Grossman SA, Phuphanich S, Lesser G, et al. Toxicity, efficacy, and pharmacology of suramin in adults with recurrent high-grade gliomas. J Clin Oncol 2001;19:3260-3266.

74. Laterra JJ, Grossman SA, Carson KA, Lesser GJ, Hochberg FH, Gilbert MR. Suramin and radiotherapy in newly diagnosed glioblastoma: phase 2 NABTT CNS Consortium study. Neuro Oncol 2004;6:15-20.

75. Shih AH, Holland EC. Platelet-derived growth factor (PDGF) and glial tumorigenesis. Cancer Lett 2006;232:139-147.

76. Louis DN. Molecular pathology of malignant gliomas. Annu Rev Pathol 2006;1:97-117.

77. Raymond E, Brandes AA, Dittrich C, et al. Phase II study of imatinib in patients with recurrent gliomas of various histologies: a European Organisation for Research and Treatment of Cancer Brain Tumor Group Study. J Clin Oncol 2008;26: 4659-4665.

78. Wen PY, Yung WK, Lamborn KR, et al. Phase I/II study of imatinib mesylate for recurrent malignant gliomas: North American Brain Tumor Consortium Study 99-08. Clin Cancer Res 2006;12:4899-4907.

79. Dresemann G. Imatinib and hydroxyurea in pretreated progressive glioblastoma multiforme: a patient series. Ann Oncol 2005; 16:1702-1708.

80. Reardon DA, Egorin MJ, Quinn JA, et al. Phase II study of imatinib mesylate plus hydroxyurea in adults with recurrent glioblastoma multiforme. J Clin Oncol 2005;23:9359-9368.

81. Desjardins A, Quinn JA, Vredenburgh JJ, et al. Phase II study of imatinib mesylate and hydroxyurea for recurrent grade III malignant gliomas. J Neurooncol 2007;83:53-60.

82. Dresemann G, Weller M, Bogdahn U, et al. Imatinib plus hydroxyurea versus hydroxyurea monotherapy in progressive glioblastoma: an international multi-center, open-label, randomized phase III study (Ambrosia-Study). Neuro Oncol 2008;Abstract MA19.

83. Fine HA, Puduvalli VK, Chamberlain MC, et al. Enzastaurin (ENZ) versus lomustine (CCNU) in the treatment of recurrent, intracranial glioblastoma multiforme (GBM): A phase III study. J Clin Oncol 2008;26(May 20 Suppl):abstract 2005.

84. Iniguez MA, Rodriguez A, Volpert OV, Fresno M, Redondo JM. Cyclooxygenase-2: a therapeutic target in angiogenesis. Trends Mol Med 2003;9:73-78.

85. Reardon DA, Quinn JA, Vredenburgh J, et al. Phase II trial of irinotecan plus celecoxib in adults with recurrent malignant glioma. Cancer 2005;103:329-338.

86. Levin VA, Giglio P, Puduvalli VK, et al. Combination chemotherapy with 13-cis-retinoic acid and celecoxib in the treatment of glioblastoma multiforme. J Neurooncol 2006;78:85-90.

87. Schmidt NO, Westphal M, Hagel C, et al. Levels of vascular endothelial growth factor, hepatocyte growth factor/scatter factor and basic fibroblast growth factor in human gliomas and their relation to angiogenesis. Int J Cancer 1999;84:10-18.
88. Abounader R, Laterra J. Scatter factor/hepatocyte growth factor in brain tumor growth and angiogenesis. Neuro Oncol 2005;7: $436-451$

89. Avraamides CJ, Garmy-Susini B, Varner JA. Integrins in angiogenesis and lymphangiogenesis. Nat Rev Cancer 2008;8:604617.

90. Reardon DA, Fink KL, Mikkelsen T, et al. Randomized phase II study of cilengitide, an integrin-targeting arginine-glycine-aspartic acid peptide, in recurrent glioblastoma multiforme. J Clin Oncol 2008;26:5610-5617.

91. Stupp R, Goldbrunner R, Neyns B, et al. Phase I/IIa trial of cilengitide (EMD121974) and temozolomide with concomitant radiotherapy, followed by temozolomide and cilengitide maintenance therapy in patients (pts) with newly diagnosed glioblastoma (GBM). J Clin Oncol 2007;25, Part 1, No. 18S (June 20 Suppl): abstract 2000 .

92. Nabors LB, Mikkelsen T, Rosenfeld SS, et al. Phase I and correlative biology study of cilengitide in patients with recurrent malignant glioma. J Clin Oncol 2007;25:1651-1657.

93. Eskens FA, Dumez H, Hoekstra R, et al. Phase I and pharmacokinetic study of continuous twice weekly intravenous administration of cilengitide (EMD 121974), a novel inhibitor of the integrins $\alpha \mathrm{v} \beta 3$ and $\alpha \mathrm{v} \beta 5$ in patients with advanced solid tumours. Eur J Cancer 2003;39:917-926.

94. Gilbert M, Lamborn K, Lassman A, et al. Tumor tissue delivery of cilengitide after intravenous administration to patients with recurrent glioblastoma $(\mathrm{GBM})$ : Preliminary data from NABTC protocol 03-02. Neuro Oncol 2007;9:525, Abstract MA39.

95. Kerbel RS, Kamen BA. The anti-angiogenic basis of metronomic chemotherapy. Nat Rev Cancer 2004;4:423-436.

96. Kim JT, Kim JS, Ko KW, et al. Metronomic treatment of temozolomide inhibits tumor cell growth through reduction of angiogenesis and augmentation of apoptosis in orthotopic models of gliomas. Oncol Rep 2006;16:33-39.

97. Herrlinger U, Rieger J, Steinbach JP, Nagele T, Dichgans J, Weller M. UKT-04 trial of continuous metronomic low-dose chemotherapy with methotrexate and cyclophosphamide for recurrent glioblastoma. J Neurooncol 2005;71:295-299.

98. Tuettenberg J, Grobholz R, Korn T, Wenz F, Erber R, Vajkoczy P. Continuous low-dose chemotherapy plus inhibition of cyclooxygenase- 2 as an antiangiogenic therapy of glioblastoma multiforme. J Cancer Res Clin Oncol 2005;131:31-40.

99. Kesari S, Schiff D, Doherty L, et al. Phase II study of metronomic chemotherapy for recurrent malignant gliomas in adults. Neuro Oncol 2007;9:354-363.

100. Perry JR, Mason WP, Belanger K, et al. The temozolomide RESCUE study: A phase II trial of continuous (28/28) doseintense temozolomide (TMZ) after progression on conventional $5 / 28$ day TMZ in patients with recurrent malignant glioma. J Clin Oncol 2008;26(May 20 Suppl):abstract 2010.

101. Strik HM, Buhk JH, Bock C, et al. Tegwondo: Development of a novel near-continuous dose-dense temozolomide regimen for the treatment of recurrent brain tumors. J Clin Oncol 2008;26(May 20 Suppl):abstract 13016.

102. Bello L, Carrabba G, Giussani C, et al. Low-dose chemotherapy combined with an antiangiogenic drug reduces human glioma growth in vivo. Cancer Res 2001;61:7501-7506.

103. Hegi ME, Liu L, Herman JG, et al. Correlation of $\mathrm{O}^{6}$-methylguanine methyltransferase (MGMT) promoter methylation with clinical outcomes in glioblastoma and clinical strategies to modulate MGMT activity. J Clin Oncol 2008;26:4189-4199.

104. Quant EC, Norden AD, Drappatz J, et al. Role of a second chemotherapy in recurrent malignant glioma patients who progress on bevacizumab. Neuro Oncol 2009;Mar 30 [Epub ahead of print].

105. Kerbel RS. Therapeutic implications of intrinsic or induced angiogenic growth factor redundancy in tumors revealed. Cancer Cell 2005;8:269-271.

106. Murdoch C, Muthana M, Coffelt SB, Lewis CE. The role of myeloid cells in the promotion of tumour angiogenesis. Nat Rev Cancer 2008;8:618-631.

107. Aghi M, Cohen KS, Klein RJ, Scadden DT, Chiocca EA. Tumor stromal-derived factor-1 recruits vascular progenitors to mitotic neo- 
vasculature, where microenvironment influences their differentiated phenotypes. Cancer Res 2006;66:9054-9064.

108. Du R, Lu KV, Petritsch C, et al. HIF1alpha induces the recruitment of bone marrow-derived vascular modulatory cells to regulate tumor angiogenesis and invasion. Cancer Cell 2008;13: 206-220.

109. Rubenstein JL, Kim J, Ozawa T, et al. Anti-VEGF antibody treatment of glioblastoma prolongs survival but results in increased vascular cooption. Neoplasia 2000;2:306-314.

110. Kunkel P, Ulbricht $\mathrm{U}$, Bohlen $\mathrm{P}$, et al. Inhibition of glioma angiogenesis and growth in vivo by systemic treatment with a monoclonal antibody against vascular endothelial growth factor receptor-2. Cancer Res 2001;61:6624-6628.

111. Paez-Ribes M, Allen E, Hudock J, et al. Antiangiogenic therapy elicits malignant progression of tumors to increased local invasion and distant metastasis. Cancer Cell 2009;15:220-231.

112. Ebos JM, Lee CR, Cruz-Munoz W, Bjarnason GA, Christensen JG, Kerbel RS. Accelerated metastasis after short-term treatment with a potent inhibitor of tumor angiogenesis. Cancer Cell 2009; $15: 232-239$.

113. Relf M, LeJeune S, Scott PA, et al. Expression of the angiogenic factors vascular endothelial cell growth factor, acidic and basic fibroblast growth factor, tumor growth factor beta-1, plateletderived endothelial cell growth factor, placenta growth factor, and pleiotrophin in human primary breast cancer and its relation to angiogenesis. Cancer Res 1997;57:963-969.

114. Carlson MR, Pope WB, Horvath S, et al. Relationship between survival and edema in malignant gliomas: role of vascular endothelial growth factor and neuronal pentraxin 2. Clin Cancer Res 2007;13:2592-2598.

115. Kamoun WS, Ley CD, Farrar CT, et al. Edema control by cediranib, a vascular endothelial growth factor receptor-targeted kinase inhibitor, prolongs survival despite persistent brain tumor growth in mice. J Clin Oncol 2009 Mar 30 [Epub ahead of print].

116. Hylton N. Dynamic contrast-enhanced magnetic resonance imaging as an imaging biomarker. J Clin Oncol 2006;24:32933298 .
117. Barrett T, Brechbiel M, Bernardo M, Choyke PL. MRI of tumor angiogenesis. J Magn Reson Imaging 2007;26:235-249.

118. Pöpperl G, Kreth FW, Herms J, et al. Analysis of ${ }^{18}$ F-FET PET for grading of recurrent gliomas: is evaluation of uptake kinetics superior to standard methods? [Erratum in: J Nucl Med 2006;47: 806]. J Nucl Med 2006;47:393-403.

119. Provenzale JM. Imaging of angiogenesis: clinical techniques and novel imaging methods. AJR Am J Roentgenol 2007;188:11-23.

120. Sathornsumetee S, Cao Y, Marcello JE, et al. Tumor angiogenic and hypoxic profiles predict radiographic response and survival in malignant astrocytoma patients treated with bevacizumab and irinotecan. J Clin Oncol 2008;26:271-278.

121. Willett CG, Boucher Y, Duda DG, et al. Surrogate markers for antiangiogenic therapy and dose-limiting toxicities for bevacizumab with radiation and chemotherapy: continued experience of a phase I trial in rectal cancer patients. J Clin Oncol 2005;23: $8136-8139$

122. Wen PY, Schiff D, Kesari S, Drappatz J, Gigas DC, Doherty L. Medical management of patients with brain tumors. J Neurooncol 2006; $80: 313-332$

123. Lai A, Filka E, McGibbon B, et al. Phase II pilot study of bevacizumab in combination with temozolomide and regional radiation therapy for up-front treatment of patients with newly diagnosed glioblastoma multiforme: interim analysis of safety and tolerability. Int J Radiat Oncol Biol Phys 2008;71:1372-1380.

124. Eskens FA, Verweij J. The clinical toxicity profile of vascular endothelial growth factor (VEGF) and vascular endothelial growth factor receptor (VEGFR) targeting angiogenesis inhibitors; a review. Eur J Cancer 2006;42:3127-3139.

125. Verheul HM, Pinedo HM. Possible molecular mechanisms involved in the toxicity of angiogenesis inhibition. Nat Rev Cancer 2007;7:475-485

126. Narayana A, Golfinos JG, Fischer I, et al. Feasibility of using bevacizumab with radiation therapy and temozolomide in newly diagnosed high-grade glioma. Int J Radiat Oncol Biol Phys 2008; $72: 383-389$ 